\title{
INTERLEAVED DC-DC CONVERTER BASED BLBUCK- BOOST CONVERTER FED BLDC DRIVE
}

\author{
CH.S.V. Prakash M.tech student ${ }^{1}$ \\ svprakash30@gmail.com \\ k. kalyani Associate professor ${ }^{2}$ \\ B. Sankara prasad HOD and Associate professor ${ }^{3}$
}

\begin{abstract}
In this paper an improved BL Buck-Boost PFC converter fed brushless direct current (BLDC) motor drive for desired speed applications has been presented. The additional inductance and power semiconductor switches gives the advantages over the conventional circuit configuration. The reliability of the circuit gets improved by proposed model. Voltage source inverter (VSI) is used to reduce the losses across the power switches. The performance of the proposed BLDC motor is evaluated over a wide range of speed control and observed in MATLAB/Simulation environment.
\end{abstract}

Index Terms - Bridgeless (BL), improved converter, brushless direct current (BLDC) motor, discontinuous inductor current mode (DICM), power quality.

\section{INTRODUCTION}

Household applications have main concern over efficiency and cost in the development of low-power motor drives. [1], [2]. In these particular applications the Proposed BLDC motor is very much suitable due to features of high flux density per unit volume, efficiency, less maintenance, and having less electromagneticinterference problems [1]. These BLDC motors are frequently used in transportation, motion control, medical equipment, HVAC, and in many industrial applications [2]-[4]. The structure of a BLDC motor has been given in [5], [6], the stator has three phase windings and the rotor having permanent magnets. The function of brushes are done by power electronic commutation, therefore called brushless DC motor and also called as electronically commutated. International Electro technical Commission (IEC) gives recommended limits of harmonics in supply current therefore power quality problems have become important issues to be considered [7].

In this paper power factor correction (PFC) is employed in order to improve the power quality of ac mains, and also reduce the total harmonic distortion (THD) of supply current. A single -stage PFC is employed over two stage PFC due to the advantage of low components used and a single switch is sufficient for dc link voltage control[9], [10]. There are two modes of operations possible in BLDC motor one is continuous conduction mode (CCM) and second one is discontinuous conduction mode (DCM) [9], [10]. In CCM, the current through the inductor or the capacitor voltage remains continuous. CCM is not cost-effective therefore DCM is preferred for low-power applications. In this paper the additional inductor and power semiconductor switches makes the system effective, increase the reliability of the proposed system, decrease the switching losses and increase the efficiency. We can obtain maximum DC voltage at DC link. As the speed of the proposed drive is proportional to the applied dc link voltage, hence, the speed control is achieved by the variable dc link voltage of VSI. 


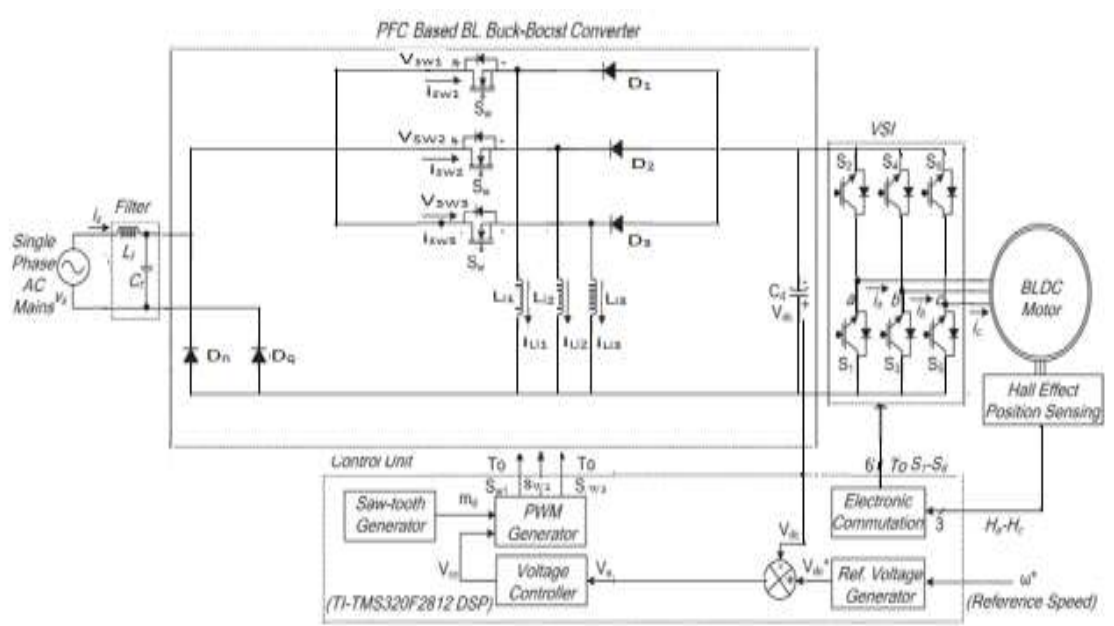

Fig.1.Proposed BLDC motor with front-end converter.

Due to pulse width modulation (PWM), majority of current and voltage sensors, VSI restricts for low-cost application [8]. For the efficiency improvement, bridgeless (BL) converter has been proposed which allows the eradication of DBR in the front end [13]-[21]. A buck-boost configuration is the one which suited best among $\mathrm{BL}$ converter types for wide range of applications.

\section{IMPROVED PFC BL BUCK-BOOST CONVERTER-FED BLDC MOTOR:}

Fig. 1 shows the Proposed BLDC motor with front-end converter. The parameters of the bl buck- boost converter are designed to perform in discontinuous mode of operation to get power factor correction at ac mains.

TABLE I

COMPARATIVE ANALYSIS OF PROPOSED BL BUCK-BOOST CONVERTERWITH EXISTING TOPOLOGIES

\begin{tabular}{|c|c|c|c|c|c|c|c|}
\hline \multirow[t]{2}{*}{ Configuration } & \multicolumn{5}{|c|}{ No. of Devices } & \multirow{2}{*}{$\begin{array}{l}1 / 2 \text { Period } \\
\text { Cond. }\end{array}$} & \multirow[t]{2}{*}{ Suitability } \\
\hline & $\mathrm{S}_{\mathrm{W}}$ & $\mathrm{D}$ & $\mathrm{L}$ & $\mathrm{C}$ & Total & & \\
\hline BL-Buck[13] & 2 & 4 & 2 & 2 & 10 & 5 & No \\
\hline BL-Boost[14] & 2 & 2 & 1 & 1 & 6 & 4 & No \\
\hline BL-Boost[15] & 2 & 2 & 1 & 2 & 7 & 7 & No \\
\hline BL-Buck-Boost[16] & 3 & 4 & 1 & 3 & 11 & 8 & Yes \\
\hline BL-Cuk T-1[17,18] & 2 & 3 & 3 & 3 & 11 & 7 & Yes \\
\hline BL-Cuk T-2[17,18] & 2 & 2 & 3 & 4 & 11 & 11 & Yes \\
\hline BL-Cuk T-3[17,18] & 2 & 4 & 4 & 3 & 13 & 7 & Yes \\
\hline BL-Cuk [19] & 2 & 3 & 3 & 2 & 10 & 8 & Yes \\
\hline BL-SEPIC[20] & 2 & 3 & 1 & 3 & 9 & 7 & Yes \\
\hline BL-SEPIC[21] & 2 & 3 & 2 & 2 & 9 & 7 & Yes \\
\hline Proposed & 3 & 5 & 3 & 1 & 12 & 8 & Yes \\
\hline
\end{tabular}

The controlling of dc link voltage using a BL buck-boost converter gives wide range of speed control with improved power quality of a proposed BLDC motor. Table-I describes connections and the number of devices or elements that are used for each configuration. In the proposed configuration the number of devices such as $\mathrm{Sw}=3, \mathrm{D}=5, \mathrm{~L}=3, \mathrm{C}=1$, Total number of components are $=12$. Even though this propose model has extra number of inductor and switches, this can have the capable of withstand the voltage fluctuations and finally can achieve the desired speed of the drive, less switching losses and higher efficiency.

\section{MODIFIED CONVERTER PRINCIPLE OF OPERATION}

The supply voltage is given to the modified bridge less converter in this situation the inductor and capacitors has been charging and discharging respectively. Whenever capacitor fully charged then the inverter starts feeding to the BLDC motor. The difference between the angle of the rotor and firing angle is sensed by the Hall Effect sensor and the error angle is given to the electronic commutation circuit in order to turn off the desired switches. To maintain the constant dc voltage, a reference voltage is compared with the dc capacitor 
voltage and the error voltage is given to the pulse with modulator (PWM). Saw-tooth generator is used to generate the saw - tooth wave form and is compared with the sinusoidal wave to generate the pulses to the modified bridge converter. As the number of levels of switches are increasing the reliability of the network has been increased.

\section{A. Modes of operation through One complete Switching Cycle}

The following three modes of operation for complete switching has been discussed for the positive cycle of the applied voltage

Mode I (inductor charging mode): in this mode of operation supply voltage is connected to excite the components and during this period the switch Sw1 is turned on hence the inductor Li1 gets short circuited. The closed path is positive terminal of the supply voltage, switch sw1, inductor Li1 and the negative terminal of the supply voltage. In this mode the inductor has been charging hence this mode is also called as charging mode of inductor.

Mode II (charging mode of capacitor): in this mode switch Sw1 is turned off. The supply voltage Vs is disconnected. As the inductor opposes the sudden changes of current, it chances the polarities and makes the diode D1 forward biased and connected to capacitor. In this mode inductor starts discharging and capacitor starts charging. After capacitor fully charged it continue to supply the stored DC energy to the inverter

Mode III (discharging mode of capacitor) in this mode the capacitor starts discharging through the voltage source inverter (VSI) feeding to the BLDC motor.

The input side average voltage for $220 \mathrm{~V}$ given as [24]

$$
V_{\text {in }}=\frac{2 \sqrt{2} V_{S}}{\pi}=\frac{2 \sqrt{2} \times 220}{\pi} \approx 198 \mathrm{~V}
$$

The general form of buck-boost converter voltage conversion ratio is given as [22]

$$
d=\frac{V_{d c}}{V_{d c}+V_{i n}}
$$

DC link voltage controlled by the improved converter

\section{B. Input Inductors Design}

Lic1 is given to continue the conduction in critical mode is given as [23]

$$
L_{i c 1}=\frac{R(1-d)^{2}}{2 f_{S}}
$$

Where,

$\mathrm{R}=\mathrm{Load}$ resistance,

$\mathrm{d}=$ duty ratio,

fs= switching frequency.

Here the calculation of minimum duty ratio (dmin) has been essential because, at minimum duty ratio the propose BLDC motor drive is operating at satisfactory voltage, power. Hence, hence Lic min is calculated as corresponding to Vdc.

$$
L_{i c \min }=\frac{V_{d c \min }^{2}}{P_{\min }} \frac{\left(1-d_{\min }\right)^{2}}{2 f_{S}}=\frac{50^{2}}{90} \frac{(1-0.2016)^{2}}{2 \times 20000}=442.67 \mu \mathrm{H}
$$

To maintain DICM mode, the values of $\mathrm{Li} 1$ and $\mathrm{Li} 2$, Li3 are taken bellow 1/10th of the minimum critical value of inductance [24]. In order to operate in DICM at peak values the supply current keeps at higher values.

B. DC Link Capacitor Design $\left(C_{d}\right)$ :

The derivation of $\mathrm{Cd}$ as follows the input power Pin is given as [22]

$$
P_{\text {in }}=\sqrt{2} V_{S} \operatorname{Sin} \omega t * \sqrt{2} I_{S} \operatorname{Sin} \omega t=V_{S} I_{S}(1-\operatorname{Cos} 2 \omega t)
$$




$$
\begin{aligned}
& i_{C}(t)=-\frac{V_{S} I_{S}}{V_{d c}} \operatorname{Cos} 2 \omega t \\
& \Delta V_{d c}=\frac{1}{C_{d}} \int i_{C}(t) d t=-\frac{I_{d}}{2 \omega C_{d}} \operatorname{Sin} 2 \omega t
\end{aligned}
$$

Where

$\Delta \mathrm{V}_{\mathrm{dc}}=\mathrm{dc}$ link voltage ripple corresponding to this capacitor current

(7) is rewritten as, $\operatorname{Sin}(\omega t)$ is taken as 1 .

Value of the $\mathrm{C}_{\mathrm{d}}$ is calculated with $3 \%$ for permitted ripple in the $\Delta \mathrm{Vdc}$ is given as

$$
\begin{aligned}
& C_{d}=\frac{I_{d}}{2 \omega \Delta V_{d c}} \\
& C_{d}=\frac{I_{d}}{2 \omega \Delta V_{d c}}=\frac{P_{0} / V_{d c d e s}}{2 \omega \Delta V_{d c}}=\frac{350 / 100}{2 \times 314 \times 0.03 \times 100}=1857.7 \mu \mathrm{F}
\end{aligned}
$$

\section{Design of Low pass second-order filter:}

In general the LC low-pass filter is placed at input side in order to filter out the higher order harmonics. Here the filter maximum values are specified in [25]

$$
C_{\max }=\frac{I_{\text {peak }}}{\omega_{L} V_{\text {peak }}} \tan (\theta)=\frac{350}{220} \frac{1}{314 \times 220 \sqrt{2}} \tan \left(1^{\circ}\right)=401.98 n F
$$

Where

Ipeak = the peak value of supply current,

Vpeak = peak value of supply voltage,

$\omega \mathrm{L}=$ line frequency in radians per second,

$\theta=$ displacement angle between the supply voltage and supply current

The value of $\mathrm{Lf}$ is derived by taking the value of $\mathrm{Cf}$ is $330 \mathrm{nF}$.

$$
L_{f}=L_{r e q}+L_{S} \Rightarrow \frac{1}{4 \pi^{2} f_{C}^{2} C_{f}}=L_{r e q}+0.04\left(\frac{1}{\omega_{L}}\right)\left(\frac{V_{S}^{2}}{P_{0}}\right)
$$

Then $L_{r e q}=\frac{1}{4 \pi^{2} \times 2000^{2} \times 330 \times 10^{-9}}-0.04\left(\frac{1}{314}\right)\left(\frac{220^{2}}{350}\right)=1.57 \mathrm{mH}$

Where

$\mathrm{fc}=$ selected cutoff frequency of the proposed filter [25]

$$
f_{L}<f_{C}<f_{S W}
$$

Here $\mathrm{fc}=\mathrm{fsw} / 10$. Finally, with inductor and capacitor a low-pass filter of $1.6 \mathrm{mH}$ and $330 \mathrm{nF}$ is taken for this application.

\section{CONTROLLING OF CONVERTER-FED BLDC MOTOR DRIVE}

The control of proposed BLDC motor is classified as two parts.

\section{A. Front-End control: Approach of Voltage Follower}

This front-end PFC control of the proposed converter generates the pulses to switches for voltage control of dc link. 


$$
V_{d c}^{*}=k_{v} \omega^{*}
$$

Where

$\mathrm{kv}=$ motor voltage constant

$\omega=$ the reference speed

The voltage error signal $(\mathrm{Ve})$ is generated as

$$
V_{e}(k)=V_{d c}^{*}(k)-V_{d c}(k)
$$

Where

$\mathrm{K}=\mathrm{kth}$ sampling instant.

The controlled output voltage $(\mathrm{Vcc})$ which is generated by the PI controller is given as fallows

$$
V_{c c}(k)=V_{c c}(k-1)+k_{p}\left\{V_{e}(k)-V_{e}(k-1)\right\}+k_{i} V_{e}(k)
$$

Where

$\mathrm{kp}=$ proportional gain

$\mathrm{ki}=$ integral gain of the PI controller.

Finally, PWM pulses are generated by the controller by comparing the reference signal with saw tooth signal of high frequency

$$
\begin{aligned}
& \text { For } v_{S}>0 ; \quad\left\{\text { ifm }_{d}<V_{c c} \text { then } S_{w 1}={ }^{\prime} O N^{\prime}\right\} \\
& \left\{\text { ifm } m_{d} \geq V_{c c} \text { then } S_{w 1}=' O F F^{\prime}\right\} \\
& \text { For } v_{S}<0 \text {; } \\
& \left\{\text { ifm }_{d}<V_{c c} \text { then } S_{w 2}=^{\prime} O N^{\prime}\right\} \\
& \left\{\text { ifm } m_{d} \geq V_{c c} \text { then } S_{w 2}=^{\prime} O F F^{\prime}\right\}
\end{aligned}
$$

B. BLDC Motor control:

Which is an electronic commutation of the proposed BLDC motor, in order to give proper switching sequence

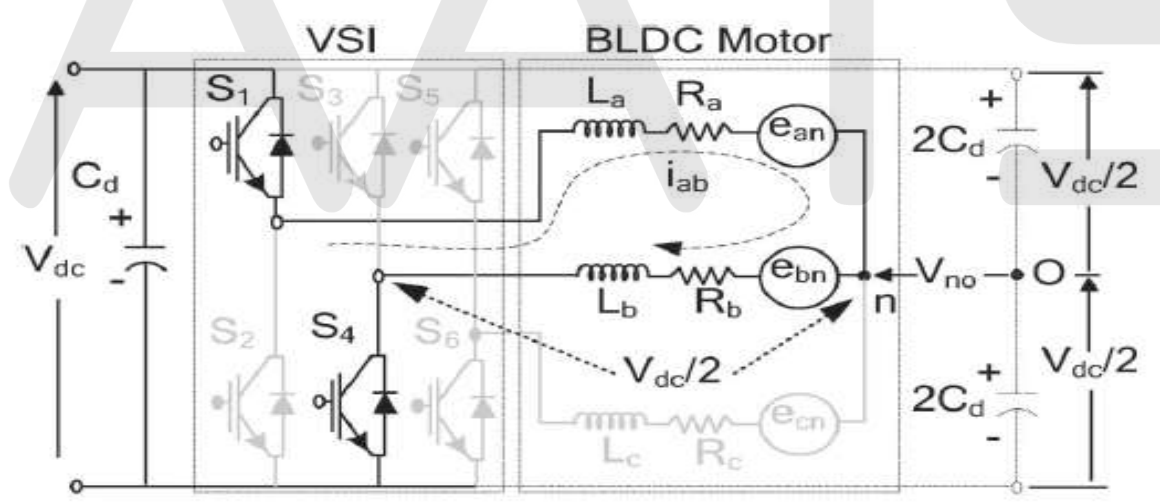

Fig.2. Operation of BLDC motor through VSI

\section{TABLE II}

SWITCHING STATES

USING HALL-EFFECT POSITION SIGNALS TO ACHIEVING ELECTRONIC COMMUTATION

\begin{tabular}{|c|c|c|c|c|c|c|c|c|c|}
\hline$\theta\left(^{\circ}\right)$ & \multicolumn{3}{|c|}{ Hall Signals } & \multicolumn{7}{c|}{ Switching Sates } \\
\hline & $\mathrm{H}_{\mathrm{a}}$ & $\mathrm{H}_{\mathrm{b}}$ & $\mathrm{H}_{\mathrm{c}}$ & $\mathrm{S}_{1}$ & $\mathrm{~S}_{2}$ & $\mathrm{~S}_{3}$ & $\mathrm{~S}_{4}$ & $\mathrm{~S}_{5}$ & $\mathrm{~S}_{6}$ \\
\hline $\mathrm{NA}$ & 0 & 0 & 0 & 0 & 0 & 0 & 0 & 0 & 0 \\
\hline $0-60$ & 0 & 0 & 1 & 1 & 0 & 0 & 0 & 0 & 1 \\
\hline $60-120$ & 0 & 1 & 0 & 0 & 1 & 1 & 0 & 0 & 0 \\
\hline $120-180$ & 0 & 1 & 1 & 0 & 0 & 1 & 0 & 0 & 1 \\
\hline $180-240$ & 1 & 0 & 0 & 0 & 0 & 0 & 1 & 1 & 0 \\
\hline $240-300$ & 1 & 0 & 1 & 1 & 0 & 0 & 1 & 0 & 0 \\
\hline $300-360$ & 1 & 1 & 0 & 0 & 1 & 0 & 0 & 1 & 0 \\
\hline NA & 1 & 1 & 1 & 0 & 0 & 0 & 0 & 0 & 0 \\
\hline
\end{tabular}


DC link capacitor provides DC current for 120o symmetrically at the center of every phase. Rotor position is estimated with the help of Hall-effect sensor during the interval of $60 \mathrm{o}$ for the electronic commutation. iab is a line current, which is drawn from the dc link capacitor and the amount of current drawn is depends on back EMF's, resistances, and finally self-inductance and mutual inductance of the proposed stator windings. Halleffect position signals are shown in Table II shows for the different switching states.

\section{Results and discussion:}

An interleaved bridgeless buck boost dc-dc converter based power processor is designed to drive BLDC motor, which is fed from ac supply. Figure 3 shows that the supply voltage which is given to proposed power processor, i.e. bridgeless interleaved based buck-boost converter. This converter can convert directly ac to pure dc without any ac-dc converter stage, and its output is shown in figure 4 . From fig 5 , it can be clearly observed that proposed converter provides constant dc as an input to inverter, and converter dc into ac to feed BLDC motor and its per unit voltage waveforms are shown in fig 5 .

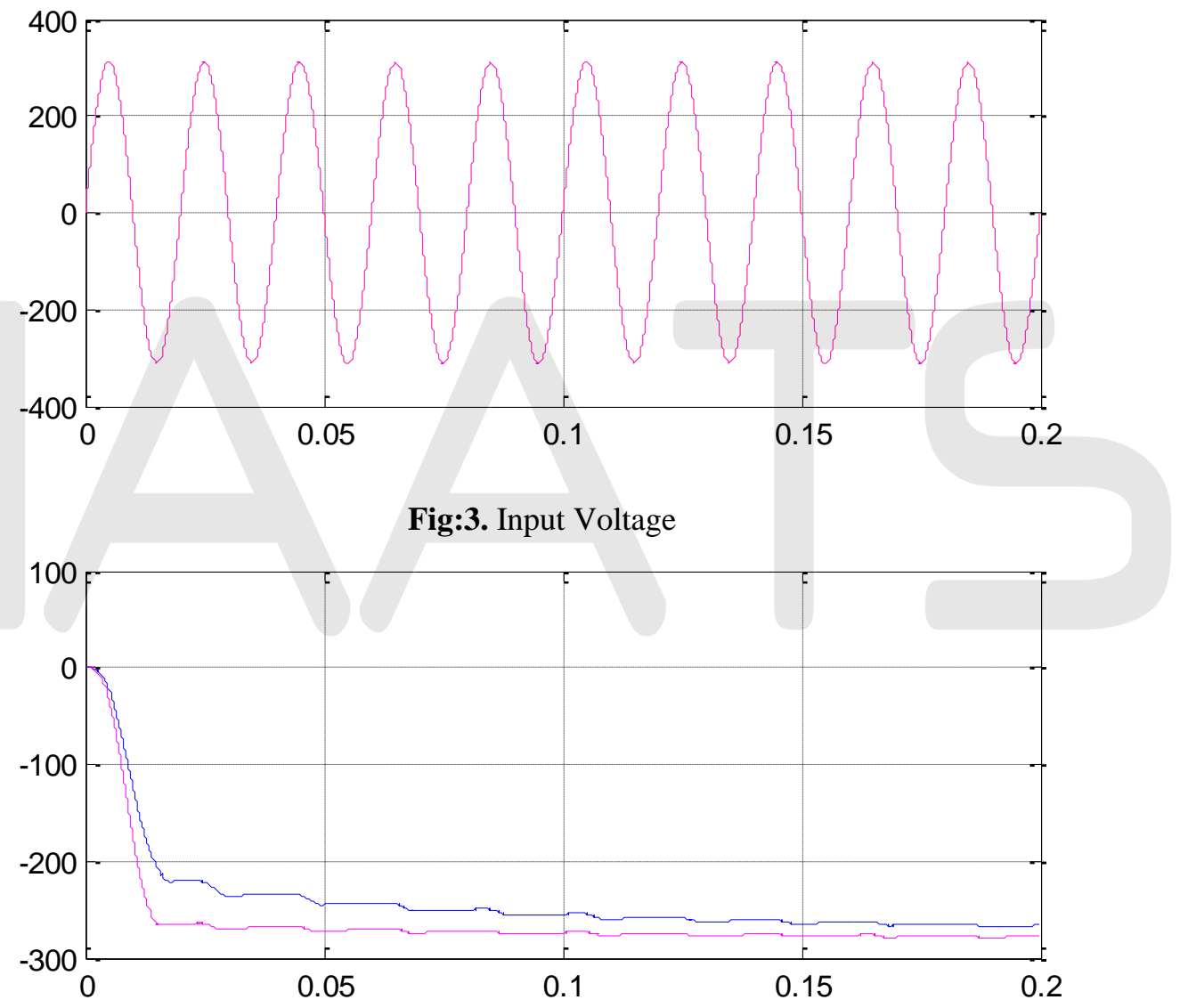

Fig:4. Capacitor DC link Voltage 


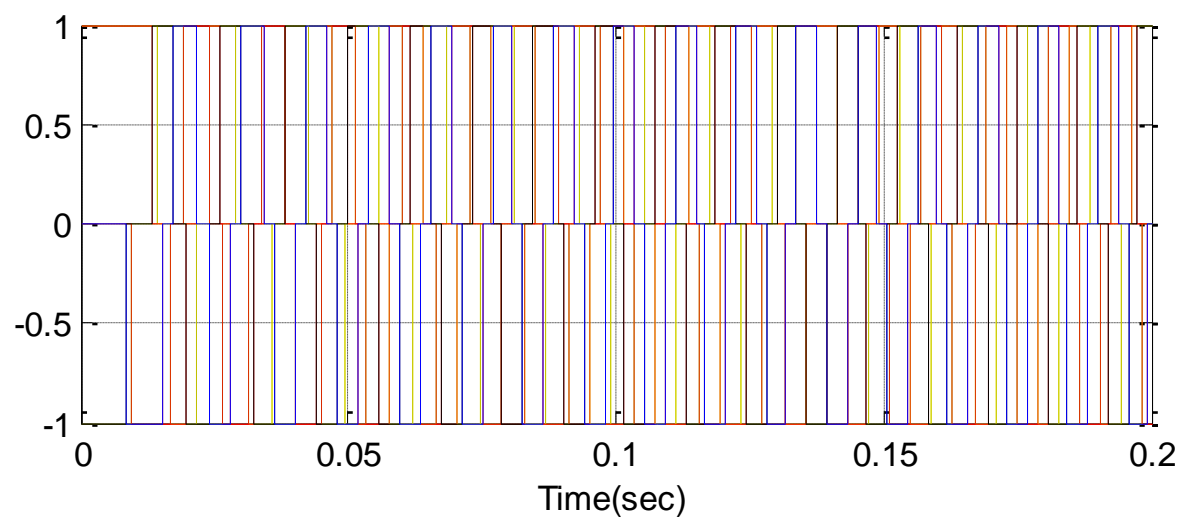

Fig:5. Three Phase Induced EMF of BLDC Drive

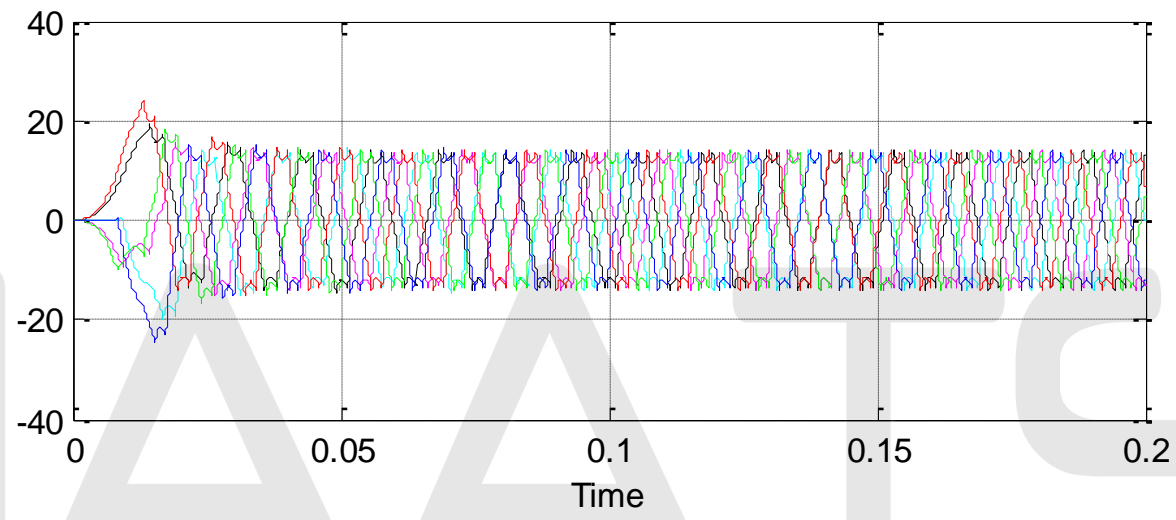

Fig:6. Three Phase Induced EMF 2 of BLDC Drive

In fig.6, currents in stator of BLDC motor are shown, and at starting or during dynamic response magnitude of currents are high as its speed is low at staring. And once machine reaches to steady state bldc motor draws constant steady state currents. BLDC motor speed is shown in fig 7, when it is being fed with 2 legs of dc-dc and 3-legs of dc-dc converter. However, BLDC motor is given best performance when its fed with 3 legs of dc-dc stage.

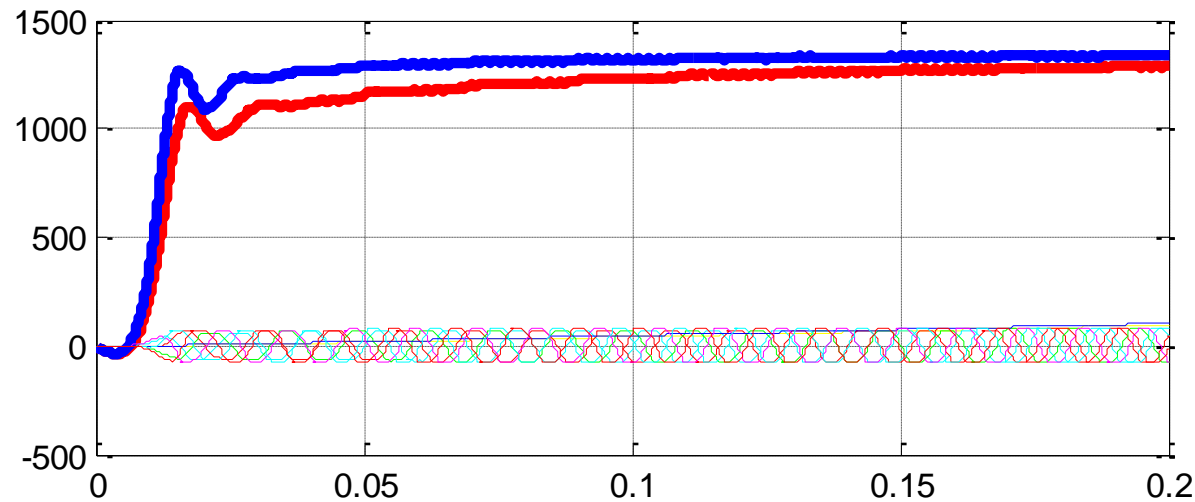

Fig:7. Output Speed of BLDC Drive 


\section{Conclusion:}

An improved BL Buck-Boost PFC converter fed brushless direct current (BLDC) motor drive for desired speed applications has presented. The additional inductance and power semiconductor switches gives the advantages over the conventional circuit configuration. The reliability of the circuit gets improved by proposed model. Voltage source inverter (VSI) is used to reduce the losses across the power switches. The performance of the proposed BLDC motor is evaluated over a wide range of speed control and observed in MATLAB/Simulation environment, all the simulation results across each element is presented.

\section{REFERENCES}

[1] C. L. Xia, Permanent Magnet Brushless DC Motor Drives and Controls. Hoboken, NJ, USA: Wiley, 2012.

[2] J. Moreno, M. E. Ortuzar, and J. W. Dixon, "Energy-management system for a hybrid electric vehicle, using ultracapacitors and neural networks,” IEEE Trans. Ind. Electron., vol. 53, no. 2, pp. 614-623, Apr. 2006.

[3] Y. Chen, C. Chiu, Y. Jhang, Z. Tang, and R. Liang, "A driver for the singlephase brushless de fan motor with hybrid winding structure,” IEEE Trans.Ind. Electron., vol. 60, no. 10, pp. 4369-4375, Oct. 2013.

[4] X. Huang, A. Goodman, C. Gerada, Y. Fang, and Q. Lu, "A single sided matrix converter drive for a brushless dc motor in aerospace applications," IEEE Trans. Ind. Electron., vol. 59, no. 9, pp. 3542-3552, Sep. 2012.

[5] H. A. Toliyat and S. Campbell, DSP-Based Electromechanical Motion Control. Boca Raton, FL, USA: CRC Press, 2004.

[6] P. Pillay and R. Krishnan, "Modeling of permanent magnet motor drives," IEEE Trans. Ind. Electron., vol. 35, no. 4, pp. 537-541, Nov. 1988.

[7] Limits for Harmonic Current Emissions (Equipment Input Current $\leq 16$ A Per Phase), Int. Std. IEC 61000-3-2, 2000. BIST AND SINGH: ADJUSTABLE-SPEED PFC BRIDGELESS BUCK-BOOST CONVERTER-FED BLDC MOTOR DRIVE 2677

[8] S. Singh and B. Singh, "A voltage-controlled PFC Cuk converter based PMBLDCM drive for air-conditioners," IEEE Trans. Ind. Appl., vol. 48, no. 2, pp. 832-838, Mar./Apr. 2012.

[9] B. Singh, B. N. Singh, A. Chandra, K. Al-Haddad, A. Pandey, and D. P. Kothari, "A review of single-phase improved power quality acdc converters," IEEE Trans. Ind. Electron., vol. 50, no. 5, pp. 962-981, Oct. 2003.

[10] B. Singh, S. Singh, A. Chandra, and K. Al-Haddad, "Comprehensive study of single-phase ac-dc power factor corrected converters with high-frequency isolation,” IEEE Trans. Ind. Informat., vol. 7, no. 4, pp. 540-556, Nov. 2011.

[11] S. Singh and B. Singh, "Power quality improved PMBLDCM drive for adjustable speed application with reduced sensor buck-boost PFC converter," in Proc. 4th ICETET, Nov. 18-20, 2011, pp. 180-184.

[12] T. Gopalarathnam and H. A. Toliyat, "A new topology for unipolar brushless dc motor drive with high power factor," IEEE Trans. Power Electron.,vol. 18, no. 6, pp. 1397-1404, Nov. 2003.

[13] Y. Jang and M. M. Jovanovi'c, “Bridgeless high-power-factor buck converter,” IEEE Trans. Power Electron., vol. 26, no. 2, pp. 602611, Feb. 2011.

[14] L. Huber, Y. Jang, and M. M. Jovanovi'c, "Performance evaluation of bridgeless PFC boost rectifiers," IEEE Trans. Power Electron., vol. 23, no. 3, pp. 1381-1390, May 2008.

[15] A. A. Fardoun, E. H. Ismail, M. A. Al-Saffar, and A. J. Sabzali, "New 'real' bridgeless high efficiency ac-dc converter," in Proc. 27th Annu. IEEE APEC Expo., Feb. 5-9, 2012, pp. 317-323.

[16] W. Wei, L. Hongpeng, J. Shigong, and X. Dianguo, "A novel bridgeless buck-boost PFC converter," in IEEE PESC/IEEE Power Electron. Spec. Conf., Jun. 15-19, 2008, pp. 1304-1308. [17] A. A. Fardoun, E. H. Ismail, A. J. Sabzali, and M. A. Al-Saffar, "New efficient bridgeless Cuk rectifiers for PFC applications," IEEE Trans. Power Electron., vol. 27, no. 7, pp. 3292-3301, Jul. 2012.

[17] A. A. Fardoun, E. H. Ismail, A. J. Sabzali, and M. A. Al-Saffar, "A comparison between three proposed bridgeless Cuk rectifiers and conventional topology for power factor correction," in Proc. IEEE ICSET, Dec. 6-9, 2010, pp. 1-6.

[18] M. Mahdavi and H. Farzaneh-Fard, "Bridgeless CUK power factor correction rectifier with reduced conduction losses," IET Power Electron., vol. 5, no. 9, pp. 1733-1740, Nov. 2012.

[19] A. J. Sabzali, E. H. Ismail, M. A. Al-Saffar, and A. A. Fardoun, "New bridgeless DCM Sepic and Cuk PFC rectifiers with low conduction and switching losses," IEEE Trans. Ind. Appl., vol. 47, no. 2, pp. 873-881, Mar./Apr. 2011.

[20] M. Mahdavi and H. Farzanehfard, "Bridgeless SEPIC PFC rectifier with reduced components and conduction losses," IEEE Trans. Ind. Electron., vol. 58, no. 9, pp. 4153-4160, Sep. 2011.

[21] N. Mohan, T. M. Undeland, and W. P. Robbins, Power Electronics: Converters, Applications and Design. Hoboken, NJ, USA: Wiley, 2003.

[22] A. Emadi, A. Khaligh, Z. Nie, and Y. J. Lee, Integrated Power Electronic Converters and Digital Control. Boca Raton, FL, USA: CRC Press, 2009.

[23] D. S. L. Simonetti, J. Sebastian, F. S. dos Reis, and J. Uceda, "Design criteria for SEPIC and Cuk converters as power factor preregulators in discontinuous conduction mode," in Proc. Int. Electron. Motion Control Conf., 1992, vol. 1, pp. $283-288$.

[24] V. Vlatkovic, D. Borojevic, and F. C. Lee, "Input filter design for power factor correction circuits," IEEE Trans. Power Electron., vol. 11 , 